\title{
Editorial
}

\section{Commentary on "The Epidemiology of Respiratory Failure in Neonates Born at an Estimated Gestational Age of 34 Weeks or More" by Clark RH, et al.}

\section{H. Frank Andersen, MD David W. Green, MD}

Journal of Perinatology (2005) 25, 501-502. doi:10.1038/sj.jp.7211348

Elective delivery holds an uncertain and controversial position in obstetrical practice. Historically, elective delivery was thought to be primarily for physician convenience, but in today's patient preference driven environment elective delivery is often done at the request, or even the insistence of patients who want to establish a specific date for their anticipated delivery. It is not clear to what extent the rapidly increasing rate of elective induction of labor contributes to an increasing cesarean section rate. Furthermore, some patients now elect to have primary cesarean delivery without labor. It is certain that if we embark upon an elective delivery, we have a responsibility to minimize the risk to the patient, in particular the risk of inadvertent preterm delivery with attendant neonatal complications.

Previous authors have noted that extreme neonatal illness, even death, may occur after elective cesarean section. ${ }^{1,2}$ To minimize these risks, the American College of Obstetrics and Gynecology (ACOG) specifies guidelines to establish term gestation prior to elective delivery. ${ }^{3}$ In summary, these guidelines recommend 39 completed weeks of gestation prior to elective delivery. If elective delivery prior to 39 weeks is planned, the clinician is advised to confirm lung maturation by amniocentesis. ${ }^{4}$ While these guidelines apply to both vaginal and cesarean deliveries, it has long been observed that cesarean delivery is associated with a higher rate of neonatal pulmonary complications than vaginal delivery. ${ }^{2,5}$ The clinician should carefully consider the rationale for elective cesarean delivery prior to 39 weeks; the alternatives — waiting until 39 weeks, awaiting the onset of labor, or amniocentesis to confirm fetal lung maturity — are generally not clinically dangerous.

The data in the Clark study provide a sobering perspective on the potential risk of elective term delivery. ${ }^{6}$ As presented in the

Baylor University Medical Center (H.F.A.), Obstetrix Medical Group of Dallas, Dallas, TX, USA; and Pediatrix Medical Group (D.W.G.), Dallas, TX, USA.

Address correspondence and reprint requests to $\mathrm{H}$. Frank Andersen, MD, Maternal-Fetal Medicine, J160, 3500 Gaston Ave, Dallas, TX 75246, USA. original article, the data do not clearly address the issue of elective delivery, but it was notable that a number of infants beyond 37 weeks were admitted to NICU after elective cesarean delivery. At our request, the Near-Term Respiratory Failure Research Group provided additional details on the newborn data. Infants were identified who had cesarean delivery, no mention of a complication that is an indication for delivery, no anomalies, and no report of antepartum or intrapartum fetal distress (Table 1).

Overall, 71 of these 133 infants (53.4\%) were delivered at or beyond 37 weeks gestational age, a gestation that is technically considered to be full-term. A total of $91(68.4 \%)$ of these infants had a diagnosis of respiratory distress syndrome, suggesting that delivery occurred prior to achieving pulmonary maturity. Other diagnoses (Table 2) may or may not be avoidable by delaying delivery until later gestation, confirming pulmonary maturity by amniocentesis, or awaiting spontaneous labor. A significant number of intensive therapies were required for these infants (Table 3).

The data of Clark et al. are limited. Delivery indication was collected from the neonatal record, which may not completely reflect the obstetrical chart. Indeed it is difficult to understand why 35 patients at 34 to 35 weeks were "electively" delivered. We know that NICU admission of a term neonate is uncommon and the Clark study provides no denominator with which to calculate the incidence of term neonatal admission. But the observation that any low-risk term infants are admitted to the NICU after an elective delivery is a cause for concern. It is difficult to explain to a family why the baby they expected to be carrying home is now in the

\begin{tabular}{|lcc|}
\hline Table 1 & Gestational Age at Elective Cesarean Delivery \\
\hline EGA & Count & Percent \\
\hline 34 & 18 & 13.5 \\
35 & 17 & 12.8 \\
36 & 27 & 20.3 \\
37 & 23 & 17.3 \\
38 & 21 & 15.8 \\
39 & 17 & 12.8 \\
40 & 9 & 6.8 \\
41 & 1 & 0.8 \\
& & \\
Total & 133 & 100 \\
\hline
\end{tabular}


Table 2 Diagnoses of Infants Admitted to NICU after Elective Cesarean Delivery

\begin{tabular}{|lrr|}
\hline Pulmonary Diagnosis & Count & Percent \\
\hline Respiratory Distress Syndrome & 91 & 68.4 \\
Pneumonia/Sepsis & 17 & 12.8 \\
Aspiration Syndrome & 6 & 4.5 \\
Transient tachypnea of the newborn & 6 & 4.5 \\
Meconium Aspiration Syndrome & 3 & 2.3 \\
No Primary Diagnosis & 3 & 2.3 \\
Primary Diagnosis — Unknown & 3 & 2.3 \\
Idiopathic persistent pulmonary hypertension of the & 2 & 1.5 \\
newborn (clear lung fields) & & \\
Surgical support & 2 & 1.5 \\
\hline
\end{tabular}

Table 3 Treatment Modalities for Infants Admitted to NICU after Elective Cesarean Delivery (Infants may have more than one treatment modality)

$106(80 \%)$ were treated with surfactant

$67(50 \%)$ received extra volume

$35(26 \%)$ received pressors

$24(18 \%)$ were treated with high frequency ventilation

19 (14\%) were treated with iNO

$10(7.5 \%)$ required oxygen at discharge or until 30 days of life

3 (2.2\%) were treated with ECM0

$3(2.2 \%)$ had abnormal neurological events -1 IVH, 2 had seizures

$1(0.7 \%)$ died

Neonatal Intensive Care Unit, perhaps on a ventilator. It is even harder to explain outcomes that include chronic lung disease, neurologic morbidity, and even death.
Good obstetrical care often requires the balancing of many factors influencing both maternal and neonatal outcome. Reasons that apparently mandate delivery in the opinion of the obstetrician may seem relatively unimportant to the pediatrician or neonatologist. Obstetrician/gynecologists are increasingly faced with pressures to perform procedures such as elective primary cesarean section, that even 5 years ago would have been unthinkable. But it remains incumbent upon us to "first do no harm." In the case of elective term delivery, this means the responsibility to insure that newborn infants do not face an avoidable risk of NICU admission.

\section{References}

1. Keszler M, Carbone MT, Cox C, Schumacher RE. Severe respiratory failure after elective repeat cesarean delivery: a potentially preventable condition leading to extracorporeal membrane oxygenation. Pediatrics 1992;89: 670-2.

2. Hook B, Kiwi R, Amini SB, Fanaroff A, Hack M. Neonatal morbidity after elective repeat cesarean section and trial of labor. Pediatrics 1997;100: 348-53.

3. The American College of Obstetricians and Gynecologists. Induction of labor ACOG Practice Bulletin, No. 10, November 1999.

4. The American College of Obstetricians and Gynecologists. Assessment of fetal lung maturity ACOG Educational Bulletin No. 230, November 1996.

5. White E, Shy KK, Daling JR. An investigation of the relationship between cesarean section birth and respiratory distress syndrome of the newborn. Am J Epidemiol 1985;121:651-63.

6. Clark RH, et al. The epidemiology of respiratory failure in neonates born at an estimated gestational age of 34 weeks or more. J Perinatology 2005; 25:251-7. 